and comparator. The Gases Laboratory is mainly concerned with the determination of oxygen, hydrogen and nitrogen in molten metal, and vacuum fusion apparatus is used, comprising a vacuum system attached to a 30-kVA. valve-oscillator type highfrequency furnace. Bone and Wheeler and Orsat apparatus for gas analysis are available. The Mechanical Testing Laboratory is equipped with a variety of machines for testing ordinary mechanical properties -tensile, transverse, compression, fatigue, impact, hardness, damping-including a 50-ton Avery single ram-type machine for determining mechanical properties at both high and low temperatures. Five types of extensometer are used, including one for elevated temperature tests. The experimental foundry is equipped to provide any of the molten metals within the Association's field and for their subsequent treatment, and immersion pyrometers and temperature recorders are used. The machine and instrument shop has a wide range of modern machine tools, such as are needed not only for the preparation of all forms of test samples, but also for the construction of apparatus made by the Association itself, including, for example, a machine for simulating cavitation erosion in propellers by a Venturi nozzle and a jet impact mazhine for measuring cavitation erosion; apparatus for annealing in controlled gaseous atmospheres; a 20 -way static strain-gauge bridge with calibration beam, and apparatus for thermal con. ductivity, thermal shock and electrical resistivity. Considerable use is made of electronic control methods.

One of the most recent extensions of activity has been the setting up of a small operational research team to which two of three appointments have been made, for the examination of foundry efficiency. The Association is also considerably interested in problems arising from working conditions in foundries, a solution of which is required, ror example, to implement the 1947 report of the Joint Advisory Committee on Conditions in Iron Foundries.

In addition to papers presented by the staff to scientific and technical institutions, reports are issued in the Association's. Journal of Research and Development, which has now been made generally available. Thirty-three reports, running to $\mathbf{4 4 5}$ pages, have apperred in the six issues published since mid-1949.

\section{MUSK AND THE MUSK DEER}

$\mathrm{T}$ HE musk deer (Moschus moschus) has been divided by modern systematists into five sub. species. The sub-species of the Himalaya region has perhaps not suffered so much at the hands of man as have the other sub-species, and is stated to be still fairly common in parts of Kashmir. But as Colin Matheson (J. Soc. Pres. Fauna Emp., 41 ; March 1950) has recently stated, all are and have been subject to severe persecution. To-day the musk deer is found in many areas in China and also in forested parts of Manchuria, Korea and Sakhalin Island; thence its range extends into the Amur region through Sibera as far as the Altai and to the West Mongolian Border. It is also found in Tibet and southwards as far as the Himalayas in northern India.

Male and female are much alike; neither carries antlers; but the male is armed with two abnormally long teeth (the canines) in the upper jaw, which is used in fights with rivals. On the abdomen the male carries the so-called musk-pod, into which a gland secretes the musk, generally described as of the colour and consistency of 'moist gingerbread' and which appears to serve for attracting the female.

This musk-pod has unfortunately proved to be a great incentive to the destruction of the animal, musk being in constant demand as raw material in the perfume industry. Like other animal perfume materials, musk is a powerful fixative for plant perfumes, and in addition its scent is so intense that in many finished perfumes it is not subordinate to other odours but is one of the predominant constituents.

The animals are caught by snaring or shooting, which results in the death of many young deer as well as females which have no musk-pods. As a result the musk deer now appears to be on the road to extinction over much of its range. In 1925 the quantity of musk exported from China and Eastern Tibet was stated to amount to about 27,000 Chinese ounces per annum, valued at $£ 100,000$. The number of animals killed annually in China and Tibet at that time was estimated to be between 10,000 and 15,000.

So valuable was musk in the perfume industry that attempts were made to prepare artificial musk, the first commerciol success being achieved by Albert Baur. The present-day musk xylon is widely used in shampoo powder perfumes but has its greatest application in soap perfumery, as it is stated to give a tablet of soap an indefinable sweetness unobtainable with other substances. Another artificial is musk ketone, stated to be the most widely used among continental perfumers. The third musk, ambrette, is the most frequently used in England. These artificial musks resemble natural musks in odour to a greater or lesser degree, but are quite different from it in their chemical composition. True musk owes its odour to a small amount of one of the ketones, known as muscone. In 1926 muscone was isolated from musk, and since then a number of synthetic products have been prepared which, although similar in chemical structure to natural musk, do not occur in Nature.

Although the use of artificial and synthetic musks has increased during the past twenty years, there is, however, still a big demand for natural musks, and the future of the musk deer is cousing considerable disquiet to animal lovers. T. H. HAwKINs

\section{MUSHROOM RESEARCH ASSOCIATION REPORT FOR 1946-48}

$T$ HE Mushroom Research Association, Ltd., represents a well-directed effort on the part of mushroom growers in Great Britain to obtain new knowledge for their own particular industry. A research laboratory was established at Yaxley, Peterborough, in $1946^{1}$, and the first report, covering the years 1946-48, is now available, following the provision of financial assistance from the Ministry of Agriculture in 1948.

Dr. R. L. Edwards, director of the Station, describes a wealth of detailed experiment leading to the specification for a successful 'synthetic' compost. 'This is, of course, necessary because very little horse manure is now available. The 'MRA' compost is made from $315 \mathrm{lb}$. wheat straw with the addition, at first stacking, of $42 \mathrm{lb}$. dried blood, $2 \mathrm{lb}$. of sulphate of potash, $7 \mathrm{lb}$. ground ehalk and $5 \mathrm{lb}$. gypsum. At the fourth turn 